\title{
Antropoliética de la educación como horizonte de una difusión cultural situada. Miradas desde la filosofía latinoamericana
}

\author{
Anthropolitical of education as the horizon of a situated cultural \\ diffusion. Views from Latin American philosophy
}

ORLANDO LIMA ROCHA

Universidad Nacional Autónoma de México, Distrito Federal, Mexico (orlimarocha@gmail.com) (https://orcid.org/0000-0003-3999-3700)

\section{RESUMEN}

El artículo busca situar la filosofía de la educación latinoamericana, desde sus linderos éticos y antropológicos políticamente definidos, concretizada en la unidad de la persona humana y la colectividad. Ello con el fin de destacar la antropoliética como categoría orientadora de una educación para la liberación. La cual, situada desde la filosofía latinoamericana, permite plantear la difusión cultural como horizonte de una práctica docente y didáctica comprometida con la realidad propia que le da cabida como política cultural.

\section{ABSTRACT}

The article seeks to situate the philosophy of Latin American education, from its ethical and anthropological politically defined boundaries, concretized in the unity of the human person and the collectivity. This is in order to highlight anthropolietics as a guiding category of an education for liberation. Based on Latin American philosophy, it allows us to raise the cultural diffusion as the horizon of a teaching and didactic practice committed to the reality that gives it space as a cultural policy.

\section{PALABRAS CLAVE / KEYWORDS}

Latin american philosophy, anthropolietics; education, liberation, diffusion, culture. / filosofía latinoamericana, antropoliética, educación, liberación, difusión, cultura. 
La educación es una opción para la libertad del hombre. [...] Para que la educación logre los niveles propuestos para la liberación y transformación de [las personas, sic.] se requiere una educación en la democracia y una democracia en la educación lo cual nos encamina a una educación autogestionaria y corresponsable, al constituirse en una respuesta alternativa y radical [...para] la formación de una ciudadanía crítica de la realidad social [...] y en la defensa de la dignidad humana. (Magallón, 1993, p. 18-9)

\section{INTRODUCCIÓN: MOTIVOS DE UNA FILOSOFÍA LATINOAMERICANA DE LA EDUCACIÓN}

Filosofar con perspectiva latinoamericana constituye un reflexionar sobre lo humano de la humanidad misma en el concierto del mundo de la vida, para situarlo en plena convivencia colectiva y normativamente situadas como signos de vida libre y justa orientada por principios (tanto desde lo personal como desde el bien común) desde una memoria de los vencidos que nos constituyen (más allá de los marcos textuales, escriturarios y de las propias huellas -vestigios, archivos, monumentos, documentos- y más acá de los símbolos y oralidades que, en conjunto, condicionan toda vida colectivamente hecha).

Es así que nuestro filosofar "adolece" de un eclecticismo, cuyas afinidades selectivas son también, y sobre todo, configuradoras de una filosofía de la educación entendida como reflexión crítica del acto educativo y su horizonte pedagógico histórico-políticamente situado. Eclecticismo que condiciona, a su vez, a una educación crítica y comprometida. Educación situada desde un campo interdisciplinario para ser desarrollada, desde todos sus ámbitos (en tanto educación formal, no formal e informal), como un medio de formación humana capaz de impulsar los cambios sociales desde las relaciones interpersonales.

De allí que una filosofía latinoamericana de la educación busque una construcción de una propuesta teórica consistente política y éticamente responsable con la persona humana y la colectividad de nuestra América toda.

Así, la filosofía de la educación tiene, en esta importante cuestión, un horizonte político fundamental, ya que el acto educativo trasciende los límites de todo profesionalismo funcional y se dirige hacia una dimensión crítica de la convivencia colectiva en torno a una integración político-cultural regional. Lo político, en este sentido, se torna en una dimensión esencial de la convivencia humana plural (sin necesaria vía de autoridad) y del acto educativo, por la cual toda filosofía de la educación crítica se torna en filosofía política de la educación.

Nuestro objetivo es reflexionar filosóficamente sobre los fundamentos ético-políticos de una práctica educativa situada para problematizar los criterios de una docencia comprometida con su propia comunidad concreta a través de la difusión cultural como acto educativo crítico y creativo desde una educación. Acto educativo que constituye uno de los puentes para transformar la educación, de un acto civilizatorio y culturalmente represivo hacia una educación para la liberación al transformar críticamente su cariz civilizatoria. Nos preguntamos entonces ¿cuál es el criterio filosófico-educativo que relacione los elementos 
planteados de una filosofía latinoamericana de la educación liberadora?

Abordamos tal cuestionamiento a partir de su dimensión antropológica, esto es, como lo llamaremos aquí, antropoliética de la educación. Tal categoría, esto es, la antropoliética, nos servirá como criterio expositivo para dimensionar no sólo la importancia, sino sobre todo el sentido que tiene una educación para la liberación humana, más allá de toda situación escolar y, por lo tanto, más allá de toda instrumentalización educativa entendida como mera instrucción y hacia una formación humana políticamente situada como horizonte cultural de toda persona humana desde las relaciones de poder. Sentido educativo que orienta una difusión cultural con sentido latinoamericanista.

Para desarrollar esta pregunta, a continuación, abordaremos la relación de una educación en sentido civilizatorio moderno, lo cual nos permitirá abordar la dimensión antropológica de la educación en tanto antropoética educativa que, situada desde su horizonte político, como educación para la liberación al transformar críticamente su cariz civilizatoria, nos permitirá plantear la difusión cultural como una forma de relación docente con la comunidad educativa desde una cultura políticamente situada, más allá de los marcos institucionales escolares y hacia un marco cultural popular. Una educación civilizatoria como cuestión antropológica desde nuestra América (I) hacia una antropoliética para una educación no colonizante (II) y por una difusión cultural latinoamericanista (III).

Tales son las cuestiones abordadas a continuación, a partir de una filosofía latinoamericana, para la problematización de una didáctica situada desde la persona humana como centro de reflexión, acción y proyección de una educación crítica y circunstanciada en su realidad histórica y político-cultural.

\section{EDUCACIÓN CIVILIZATORIA: RAÍZ ANTROPOLÓGICA DESDE NUESTRA AMÉRICA}

Es sabida la noción kantiana de la educación como medio para lograr la civilización, la cual se realiza con distintos elementos como la disciplina, la cultura, la civilidad y la moralidad. De ellas, según su Pedagogía, la disciplina es vista por el filósofo alemán como sinónimo de represión de animalidad y contención de la barbarie: «Disciplinar es tratar de impedir que la animalidad se extienda a la humanidad, tanto en el hombre individual, como en el hombre social. Así, pues, la disciplina es meramente la sumisión de la barbarie» (Kant, 2003, p. 38).

En tal sentido, la educación se constituye como sinónimo de humanización, enculturación en términos antropológicos, que permite al ser humano salir de su "minoría de edad" y ayudarle en la elección de la autonomía como alejamiento del "mal radical" humano anulador de toda vida libre e intelectualmente constituido. Disciplinamiento que tendrá su profundización y paroxismo en Lancaster y "la letra con sangre entra" como símbolo de la educación antigua. Elementos que afianzaron a su vez la memorización como técnica o mnemotecnia que arranca desde un "marcador somático" (como lo plantearan tanto los antiguos griegos y romanos, hasta algunos neurobiólogos actuales) que vincula las emociones en el razonamiento y la toma de decisiones y «consiste en establecer una serie ordenada de lugares y en asignar a cada una de ellas una marca o imagen relacionada con aquello que se 
quiere recordar» (Bartra, 2014, p. 144).

Recordemos que la llamada mnemotecnia fue creada en el siglo IV por Simónides de Ceos (ca. 556 a.C.-468 a.C.) como acto de memorización empleado para grabar datos y huellas de importancia para los sujetos implicados con base en las emociones y el subconsciente en sentido metódico con el "marcador somático" citado, empleado hasta la actualidad como "pedagogía de la memoria" o "ars memoriae" que, en último término, citando a Ricoeur, se trata de una memoria artificial que "es una negación exagerada del olvido y, poco a poco, de las debilidades inherentes tanto a la preservación de las huellas como a su evocacion» (Ricoeur, 2003, p. 93).

De tal modo que disciplina (Kant), castigo (Lancaster) y memorización (Simónides de Ceos) son tres pilares de lo que se conoce en la historia de la educación como "educación tradicional”. Sin embargo, más allá de disquisiciones históricas de la pedagogía, sin duda sugerentes, queremos destacar la cuestión de la educación como sinónimo de humanización y “sumisión” de la barbarie por vía disciplinaria y la cuestión antropológica consecuente. Más, ¿cómo se da este proceso?

En Discurso desde la marginación y la barbarie Leopoldo Zea denota la cuestión de la civilización y su negación, la barbarie, como estructura diahistórica existente en la humanidad, mostrada a lo largo de la historia occidental. De tal forma, Zea nos planteará la barbarie como un problema de "naturaleza humana" en términos aristotélicos cuando apunta que:

\begin{abstract}
Esta idea de los griegos acerca de los bárbaros, como entes limitados racional y volitivamente, la extenderá Iberia en la conquista y colonización de América a partir del siglo XVI. Es la concepción aristotélica, recogida por el tomismo, aplicada a la ordenación del mundo conquistado por los íberos. [...] El hombre es igual a todos los hombres por la razón, pero será desigual por las limitaciones que la misma naturaleza física del hombre impone a esta misma razón (Zea, 1988, p. 33).
\end{abstract}

Se habla así de una barbarie a "salvar" desde la antigua Grecia, pasando por la antigua Roma y el cristianismo que irrumpe y configura propiamente el mundo occidental (del logos, al derecho y hacia el cristianismo) fragmentada entre el imperialismo íbero-católico del siglo XV al XIX (salvacionista-personalista) y el ruso-ortodoxo sobre todo desde el siglo XIX (salvacionista-comunitarista); hasta una barbarie hegemónicamente "individualizada" (no salvacionista-individualista) que debe buscar por sí misma su propio desarrollo modelado, ciertamente, desde lo que hoy conocemos como mundo capitalista moderno anglosajón (británico primero, norteamericano después). Esto es, el misioneísmo ibérico, el mesianismo eslavo y la predestinación anglosajona como expresiones del mismo mundo cristiano civilizatoria e imperialistamente configurado (católico, ortodoxo y protestante respectivamente).

De allí que la educación sea el medio, kantianamente dicho, para el control de la barbarie hasta su sumisión civilizatoria por medio de la disciplina como objetivo de una "salvación personalista" desde la lucha por la autonomía social. El problema de la barbarie como sinónimo de ignorancia estriba entonces en la aristocratización de una ontología deshistorizada y esencialista que atribuye la condición de "civilizado", "barbarie" o "salvajismo" como algo connatural a la persona humana, una "ontocracia”, en términos de Ardiles (1975, 
p. 18), en tanto modo de ser y existir elitistamente definido. Cuestión que se agudiza más allí donde la etnicidad representa un grado menor aún al de la barbarie (incivilizado no occidental) y aún al del primitivo (occidental no civilizado) para configurarse en ellos como su degradación ontológica.

\section{Etnicidad que, al}

impedir el buen uso de la razón", queda esencializada en su accidentalidad hasta el punto de constituir a toda persona "iguales por la razón, pero extraordinariamente distintos por el uso de la misma. [...] Es una desigualdad que acabará siendo insuperable. [...] Esta degradación se extiende así a hombres y pueblos enteros. El europeo, al mestizarse con pueblos inferiores, deja de ser superior, adquiriendo la bajeza de la etnia con la que se ha mezclado (Zea, 1988, pp. 224-225).

La barbarie como limitación se agudiza en la etnicidad como degradación. Se pasa de un determinismo racial (barbarie limitada racionalmente) a un prejuicio racial (etnicidad degradada civilizatoriamente) como sinónimos de "naturaleza humana" fijada desde el poder de dominio político estatal. Aquí la educación kantiana no soluciona el problema, pues persiste la degradación racial. La cuestión llega así a una cuestión más compleja, pues la solución propuesta para la superación de la etnicidad como situación humana no es la educación, entendida enculturadamente, sino su reconocimiento como fenómeno gestado en la civilización y, por ende, en la cultura hegemónica en turno, para su precisa anulación y asesinato. Tal cuestión es entendida por la antropología, de la pluma de Pierre Clastrés, como etnocidio en tanto aceptación del mal y asimilación yuxtapuesta a una cultura civilizatoriamente dicha. Esto es,

El etnocidio es, pues, la destrucción sistemática de los modos de vida y de pensamiento de gente [sic.] diferente a quienes llevan a cabo la destrucción. El etnocidio se ejerce por el bien del Salvaje. [...] Pero si bien es cierto que toda cultura es etnocéntrica, sólo la occidental es etnocida. De esto se concluye que la práctica etnocida no se articula necesariamente con la convicción etnocéntrica. [...] El análisis del etnocidio implica, más allá de la denuncia de los hechos, una interrogación sobre la naturaleza, históricamente determinada, de nuestro mundo cultural. Por lo tanto, es necesario volverse hacia la historia. [...] La violencia etnocida, como negación de la diferencia, pertenece a la esencia del Estado [...pues] toda organización estatal es etnocida, el etnocidio es el modo normal de existencia del Estado (Clastrés, 1987, pp. 56-57, 59, 62).

Es aquí que dimensionamos la idea de una humanidad como sinónimo de civilización. Más, ¿qué entender entonces por civilización? Si la barbarie alude al desconocimiento de lo humano en la otredad, tal desconocimiento se da violentamente en una relación explosiva de violación material y simbólica que se gesta por sobre otros grupos humanos. Esto es, más allá de la noción aristotélica, puede decirse que 
Los bárbaros son aquellos que niegan la plena humanidad de los demás [...pues] se comportan como si los demás no fueran humanos o no lo fueran del todo. [...] Lo bárbaro o lo civilizado son los actos y las actitudes, no los individuos y los pueblos [... y pueden entenderse como] actos [que] tienen su origen en la misma "pulsión de vida" que nuestros actos de amor [y operan como] dos categorías morales que nos permiten evaluar actos humanos concretos (Todorov, 2013, pp. 33, 40, 44).

En tanto actitud, la barbarie se torna entonces en una dimensión cultural que se da en el mismo seno de la civilización, la cual, desde la perspectiva de Norbert Elías (2019, pp. 130-138, 210-211, 298), tiene en el pudor un eje esencial del proceso de la civilización occidental que afecta a estructuras psíquicas y sociales, ya que sería un malestar que permite interiorizar temores ante la amenaza de un agente externo y los peligros interiores suscitados en un régimen de civilidad que actúan con violencia. El higienismo se torna en ideología civilizatoria que la convierte en bárbara y actúa violentamente sobre los cuerpos que somos (Silvero, 2014).

Puede, por ende, afirmarse que toda cultura considerada hoy como civilizada tiene en su seno una dimensión de barbarie que late en su interior filogenético, que se expresa en el etnocentrismo de toda cultura y tiene en el etnocidio la regla a toda superación de "etnicidad" existente desde y más allá de la civilización occidental.

La cultura occidental así, al ensimismarse, se torna egocentrista y hasta narcisista, esto es, se barbariza. Es allí que toda civilización se torna necesariamente violenta y existe ya como barbarie opresiva, ya como salvajismo reprimido que la constituyen como violencia cultural. Allí donde lo civilizado configura su propia "pulsión de barbarie», en términos de Todorov (2013, p. 43), que, al igual que en Freud, denota «la terrible necesidad de la conexión interior entre civilización y barbarie, progreso y sufrimiento, libertad e infelicidad» (Marcuse, 1965, p. 33). Cuestión que se complejiza retomando los argumentos de Zea y Clastrés, según los cuales sólo la cultura occidental es etnocida, en tanto aculturadora de las otredades diferentes a la propia cultura a partir de relaciones con otras culturas (de modos ya multiculturalmente, inculturadamente, interculturalmente o aun transculturalmente) que conllevan una violencia que asesina culturas a partir de atentar contra su memoria y teniendo a América como el territorio civilizatorio transoccidental por excelencia desde el siglo XVI, sin dejar de lado las situaciones existentes en otras regiones del mundo.

En este marco, la educación como parte de un proyecto occidental civilizatorio moderno ha sido pertinente para hacer sumisas las experiencias de barbarie, mientras se tornó en reconocimiento para la anulación de culturas étnicamente distintas como las americanas, violentamente occidentalizadas bajo una "cultura de dominación". Cultura que, desde nuestra América, se convierte en educación colonizada:

Educación que se hacía partir de la supuesta inferioridad étnica y cultural de los colonizados. Inferioridad que abarcaba a todo nacido en esta región, ya con independencia de su origen étnico y cultural. [...] De acuerdo con tal idea, todo nativo tendría que ser educado para mejor servir a la metrópoli, para mejor satisfacer sus intereses y mejor realizar sus proyectos. [...] Hombres educados para la servidumbre poco podían hacer para organizarse como naciones y, menos 
aún, como comunidades multinacionales tal como la soñada por Bolívar para esta región de América. [...] Habrá entonces que partir de las experiencias que se tengan, de la misma servidumbre, para que no vuelva a repetirse. [...] Haciendo de la educación y la cultura instrumento de esta liberación y de la integración que estos mismos pueblos han de mantener entre sí. [...] Educando para la libertad y la integración en la libertad, a partir del pleno conocimiento de la realidad que ha de ser transformada (Zea, 1986, pp. 99-109).

Es en este sentido que, puede decirse en apretada síntesis, la educación como parte de un proyecto occidental civilizatorio moderno ha sido pertinente para hacer sumisas las experiencias de barbarie, mientras se tornó en reconocimiento para la anulación de culturas étnicamente distintas como las americanas, violentamente occidentalizadas. La memorización ha jugado aquí un papel central. Por tanto, es posible afirmar que toda educación supone una antropología filosófica de fondo que, aunque no sea explícita si es decisiva por cuanto a las finalidades sociales, culturales, históricas y políticas se refiere para la construcción de una comunidad ontológicamente igual en su diferencia. Educar, en definitiva, "es construir y desarrollar la inteligencia y la razón de los educandos, para resolver los problemas inmediatos y trascendentes de la existencia" desde el autodescubrimiento y cultivo de la propia identidad en integración personal, social y colectiva» (Magallón, 2010b. p. 246).

Ante tal sentido de la educación, se hace necesaria una reflexión sobre su papel, no sólo dentro sino, sobre todo, "fuera" de toda institución educativa. Papel que permita construir puentes de comunicación para una toma de conciencia asumida comprometidamente. Por ello nos preguntamos ¿cómo entender una antropología que constituya una educación para la liberación integral humana que la realice desde la igualdad humana fincada en la diferencia? Es aquí que la ética se constituye antropológicamente para formular la proyección de una educación para la liberación humana integral.

\section{ANTROPOLIÉTICA PARA UNA EDUCACIÓN NO COLONIZANTE}

En opinión de Edgar Morín, la antropoliética supone una ética propiamente humana que se oriente por una "decisión consciente y clara" de asunción de la condición humana subjetiva, mundana y cósmica (individual, social y de especie), de logro de humanidad en conciencia propia y de la alteridad. En definitiva, "conlleva, entonces, la esperanza de lograr la humanidad como conciencia y ciudadanía planetaria» desde la más íntima personalidad. De allí que, siguiendo la máxima de Terencio, donde nada humano nos sea ajeno, así como el cosmopolitismo de Diógenes, la democracia y el horizonte planetario se convierten en criterios de realización humana para situar el diálogo en un pólemos constituido de voluntad de comprensión humana, más allá de una disciplina o una cultura determinadas. Esto es, una antropoética que configure una comunidad política planetaria a partir de la polémica

social y su resolución por vía racional del diálogo y la discusión para una mutua 
comprensión (Morín, 1999). Antropoética así entendida que, para el filósofo Mario Magallón, tiene que constituirse como

\begin{abstract}
reflexión sobre la obra humana y social de una comunidad en el tiempo, en la historicidad, de la proyección y trascendencia en la paideia, en el areté, en los ideales del ser humano y social que se quiere educar y "cultivar". Por lo mismo, esto deberá constituirse en el proyecto de la sociedad, del ciudadano y del sistema mundial de la actualidad (Magallón, 2010, pp. 12-13).
\end{abstract}

Esto es, una antropoética política de la educación que concibe al ser humano y la humanidad toda en su más cruda onticidad y conclusión, desde la dimensión abierta y concreta de vida. Allí donde acontece como fenómeno y esencia de una colectividad que la constituye, destacando la dimensión educativa como abierta desde el diálogo, la polémica y la crítica para una comprensión política de su ser y su quehacer. De allí que la dimensión política, en tanto que signo de colectividad humana, le sea constitutiva. La cuestión es ¿qué relaciones existen entre la antropoética y el acto educativo?

Es aquí que destacamos una relación fundamental: la de la concepción misma del ser humano como persona y no ya como personaje. Allí donde, el horizonte de realización sea la persona humana sea libertad total al no afectar a nada, a nadie ni a sí mismo. Allí donde el sacrificio de la persona humana entendida como personalidad sea un modelo de trabajo para su superación, expresamente en la dimensión ritual de la educación, instituida bajo el cumplimiento de horarios, deberes y disciplina. Cuestión que se ve agravada por la relación con la tecnología, como criterio exclusivo de educabilidad y finalidad última de toda instrucción escolar.

Es entonces que la antropoética de la educación se torna en una crítica de toda alienación humana, pues «la tecnología, como juego de lenguaje y, por lo mismo, como forma de vida, crea adicción. El hombre occidental ha perdido la relación con el espacio y con el tiempo sagrados y se ha convertido en prisionero de un tiempo y un espacio desimbolizados y desmitificados. El ser humano occidental ha quedado encerrado en los barrotes del «concepto» científico» (Mélich, 1996, p. 110).

Por lo cual se hace necesario, hoy más que nunca, recuperar al ser humano de posiciones antihumanistas guiadas por un nihilismo sacrificial de la persona humana, de éticas indoloras y de políticas deshumanizantes y etnocidas. Es por ello que una antropoética de la educación tiende hacia la dialogicidad para la realización de la comprensión humana pluralmente realizada y políticamente abierta al cambio comunitario de formas de vida solidaria, equitativa y digna. Por lo cual, se configura la vuelta de lo reprimido, del ritual, de lo mítico y de lo simbólico como estructuras vitales humanas (aún desde la tecnología como campo pretendidamente independiente de estas formas de expresión vital humana).

Pueden así retomarse las palabras de Mélich, pues «antropología y pedagogía andan de la mano respecto al olvido de lo simbólico, de lo mítico y de lo ritual; de lo nocturno, en definitiva, porque sólo han utilizado un camino para acceder al estudio de la realidad humana: el racional, el tecnocientífico» (Mélich, 1996, p. 14). Ello nos permite plantear la antropoética como "antropoética política de la educación" que podremos, desde ahora, llamar antropoliética de la educación. 
Es dentro de este marco antropoliético que la educación es entendida, no como un acto de adiestramiento (condicionamiento de las conductas realizadas) ni menos aún como elemento de instrucción (mera transmisión de información de conocimientos utilitariamente dirigidos a determinados fines externos a la persona que los recibe), sino más bien como un acto político que da forma a aquello que existe ya en la persona humana para un pleno desarrollo en vida colectiva: lo humano de la humanidad, situado en aquella pluralidad de la que nos hablara Arendt, para constituir una vida auténticamente comunitaria, más allá de los marcos sacrificales de lo social (políticamente configurados siempre por vía de una autoridad absolutista en su seno).

Esto es, que la educación se posiciona desde una antropoética como un acto comunicativo en su seno, que busca realizar la libertad humana a partir de aquella dignidad que nos constituye como entes vivientes y que orienta nuestros actos mentales y de memoria humana para una auténtica relación vital con el otro. Aquella antropoética de la que nos habla el filósofo y educador Mario Magallón Anaya, posicionada más allá de todo «modelo educativo», que es en definitiva un "modelo de instrucción» en nuestros términos, que se propone ya no sólo para la formación humana sino también, y más urgente aún, para el auténtico rescate del ser humano de las entrañas civilizatorias represivas y aherrojadoras de nuestra propia creatividad.

Por lo anterior, es necesario replantearse filosóficamente la educación, no tan sólo para reflexionar sobre el mero acto educativo, materia de una pedagogía comparada en tanto instrumental, como quiere el filósofo y pedagogo mexicano José Manuel Villalpando (1966), sino sobre todo, y en esto me parece que estriba la finalidad de una antropoliética educativa, para el rescate pleno del ser humano de una vida.

Rescate que, hoy más que nunca, ha sido no sólo negada sino sobre todo acallada en cuanto reprimida por un conjunto de instituciones que apelan a una vida pretendidamente heterónoma al instar (apelar a nuestra "interioridad" como personas humanas) un mero comportamiento impuesto cultural y socialmente, sin tomar en cuenta el elemento vital de toda instancia: la mera comunicación con la otredad. De la que se deriva que «Educar [...] no es solo ni principalmente enseñar a otro un acervo de saberes más o menos rico y profundo, sino conseguir que una persona pueda y sepa decir con alguna verdad, como Don Quijote: "Yo sé quién soy» [...] el fin del pedagogo sea la personal perfección del educando, y no [sólo] «la enseñanza» (Entralgo, 1968 II, p. 256, 291).

Por lo anterior, el acallamiento institucional al que nos referimos se sitúa no solamente en aquellas instituciones de educación (de Estado o transnacionales), sino en todas aquellas formas de vida instituida (desde la familia, la propiedad privada, el Estado y las transnacionales) que no comunican, sino que meramente emiten información (órdenes, sugerencias, etcétera) sin un auténtico diálogo con la comunidad que la constituye, condiciona y le da forma (Ricoeur, 2009, pp. 69-79, 95-107). En definitiva, nos referimos a todo modo de vida institucionalizado e institucionalización que se olvida del mundo de la vida cotidiana, comunitaria y personal.

Es ante tal problemática que es preciso destacar el proyecto de una antropoliética de la educación, más allá tanto de las instituciones escolares (educación formal) como de las no escolares (que no escolarizadas, de educación no formal), y más acá de las formas y actos educativos no escolarizadas (o de educación informal) que residen en el seno de la 
vida plural y colectiva, más allá de los marcos sociales y de Estado vital. Un proyecto que se plantea, siguiendo a Magallón, el rescate del ser humano, en cuanto rescate de los vencidos y su memoria, agregamos nosotros, por cuanto aquellos vencidos a los que nos referimos están no solamente en el pasado histórico, sino también en un presente históricamente situado: son aquellos sujetos que han sido robados, despojados, de su propia dignidad para dejarles el silencio impuesto por el hambre, las discriminaciones peyorativas de todo tipo y su manipulación en la esfera política, económica y cultural como "comunidad política» formalizada y desligada de su esencial «bloque social» que los configura, no sólo como oprimidos, sino también como reprimidos, marginados y excluidos de una vida civilizatoriamente privilegiada aunque anclados en su inclusión despectiva y oclusiva. Allí donde no existe un acto comunicativo propiamente dicho desde la vida institucionalizada, sino solamente una objetualización de la otredad y, con ello, negación de la propia dignidad humana de todas las personas que constituyen una colectividad concreta.

Por ello, pensamos, es preciso configurar esta dimensión educativa en su sentido antropoliético como uno de los elementos imprescindibles para rescatar al ser humano pasado y presente. Rescate que permitirá colaborar en la proyección de un mundo de vida futuro más propio de una vida reparada, donde el perdón, la reconciliación y una memoria sin sufrimiento sean no sólo buscadas sino también realmente posibles y concretamente utópicos. Allí donde la educación se transforma de su mera instrumentalización a ser un medio de cultivo interpersonal y colectivo más allá de los marcos escolares de su desempeño y hacia lo que desarrollaremos, a continuación, como difusión cultural latinoamericanista.

\section{DIFUSIÓN CULTURAL LATINOAMERICANISTA PARA UNA DESCOLONIZACIÓN EDUCATIVA}

Hablar de difusión cultural latinoamericana es, hoy más que nunca, un proyecto colectivo que tiene, en sus cimientos, una raíz educativa. Abordar la difusión cultural desde esta raíz es, hoy más que nunca, urgente en el contexto de modelos actuales hegemónicos (educativos y político-culturales) que han dejado de lado a la persona humana por una supuesta calidad institucional contable y economicista.

En efecto, siguiendo a Leopoldo Zea en Sentido de la difusión cultural latinoamericana (1980), la difusión cultural es una de las tres grandes tareas de la educación, sobre todo en el nivel superior, junto a la función docente y la función de investigación. Funciones que son constitutivas de todo educador con vocación (en este caso, desde un ámbito formal). Pero es a partir de la difusión cultural que las funciones docentes e investigativas cobran todo su sentido social institucional: sólo así las instituciones podrán sortear el academicismo puro, que profesionaliza sin compromiso social, informa sin criticar, manipula sin racionalizar y que instruye sin educar.

Es gracias a la difusión cultural que es posible dimensionar los campos histórico-social y político-cultural que dan cabida, condicionan y dotan de sentido al acto educativo públicamente situado en su realidad concreta. Por eso, en términos de Zea, podemos decir que la difusión cultural es esencialmente un proceso de comunicación masiva crítica de 
información entre instituciones culturales y la comunidad humana, sobre todo aquella no necesariamente escolarizada (ni aún no formal o informalmente). De allí que afirme Zea, la difusión cultural es más bien una capacidad que se dirige

\begin{abstract}
al Ilamado hombre de la calle. [...] Lo importante, y en esto está el papel esencial de las instituciones de la cultura superior, será el capacitar al que recibe esta información masiva e, inclusive, manipulada, el enseñar a discernir, criticar, seleccionar de acuerdo con el propio criterio y no de acuerdo con quienes manipulan estos instrumentos. Abigarrada multitud de posibilidades, pero a partir de la capacidad crítica para su elección. Sin esta capacidad, las funciones educativas de instituciones como éstas de las que hablamos, acabarían siendo, simplemente, nulificadas. La anti-cultura acabaría imponiéndose en beneficio de quienes, a partir de su propia lógica y beneficio, la utilizan (Zea, 1980, p. 15).
\end{abstract}

La difusión cultural se apoya en los medios masivos de comunicación, muy a pesar de que estos pueden muchas veces generar una «sobreinformación» que conlleva no sólo una saturación de la memoria colectiva o "sobrememoria» (Todorov, 1996), sino también, y muy especialmente, pueden anular la racionalidad educativa y cultural. Por ello, para Zea, la difusión cultural es esencialmente una tarea política de las instituciones de educación (superior) y su objetivo es la colaboración e integración de tales instituciones con una cultura llamada popular, a partir de transformar las «limitadas políticas de difusión y adoptar, lo que en nuestros días se llaman ya políticas culturales. Esto es, políticas que plantean y replantean la temática que circula en la calle, que entra a los hogares, penetra en la sociedad, para hacerla racional, críticamente» (Zea, 1980, 15). Políticas que, desde la segunda posguerra, han representado un derecho humano que deben garantizar los gobiernos en turno para una cultura de comprensión y por una morada común, planetariamente vivida: el derecho a la cultura se convierte en acción política institucionalmente obligada y socialmente demandada por un pluralismo humano.

La relación de la difusión cultural con la cultura misma es, esencialmente, una relación dialéctica y tiende, siguiendo a Zea, hacia lo que comúnmente llamamos «cultura popular». En este sentido, la cultura podemos entenderla como expresión de un necesario ocio cotidiano, que pasa por un marco histórico-estructural que satisfaga y garantice las necesidades corporales de los hombres y pueblos con las necesidades espirituales que las dotan de sentido a una vida digna, libre y diversa, esto es, de un marco de acción humana donde la pluralidad ha sido utópicamente configurada desde un marco histórico opresivo y represivo, una realidad que "ha venido respondiendo a estímulos que no siempre nacen de sus propias necesidades» (Zea, 1980, p. 28).

En regiones occidentalmente colonizadas como nuestra América, la cultura se convierte en cultura de liberación como proyecto planteado desde una cultura de dominación realmente existente. Tal es el sentido del diagnóstico cultural latinoamericano, cuando Zea afirma que

pese a la conciencia de desarraigo, algo habría de común entre los hombres de esta región latinoamericana, la protesta. La subversión permanente, la rebelión 
contra las múltiples injusticias de que eran objeto todos los nacidos en esta tierra, todos los herederos del destierro. Se da una historia común, de libertades, que se inicia precisamente en el Caribe, donde antes se iniciase la conquista. [...] La temática central en esta región, por lo que se refiere a la elaboración de políticas culturales, va a tener dos preocupaciones, la de identidad y la de la integración. [... Políticas culturales que están condicionadas por] la falta de conciencia de un destino común [con Asia y África], el del colonialismo y el neocolonialismo. En este sentido, la búsqueda de la identidad latinoamericana va a ser vista como punto de partida de la integración (Zea, 1980, pp. 55-56).

Con base en este diagnóstico es que podemos afirmar que toda auténtica cultura es expresión de la persona humana concreta, desde su dimensión antropológica históricamente situada y tendiente a una universalidad diversa. Es aquí que la difusión cultural influye en la cultura al pasar necesariamente por el cuestionamiento de toda cultura elitista y toda cultura de masas, para configurar un proceso de comunicación realmente común a todas las personas humanas para relacionar a todos los sujetos, todas las culturas y todos los pueblos concretos entre sí. Por lo cual, una cultura colectiva que se relaciona con una difusión cultural en el sentido aquí planteado, puede ser llamada, con toda propiedad, una cultura popular que es también una cultura descolonizada en tanto que «la descolonización del hombre y la cultura de que somos parte y expresión, ha de venir de nosotros mismos» (Zea, 1974, p. 54).

Justamente, para asimilar inventivamente (inventar, para no errar, parafraseando al maestro de Simón Bolívar, el también profesor Simón Rodríguez) es preciso identificar a nuestros pueblos de nuestra América como premisa necesaria para toda integración. A partir de políticas culturales institucionalmente garantizadas para una auténtica difusión cultural, es que las distintas instituciones educativas, como las universidades, han establecido su misión educativa, que se complejiza con los "poderosos medios de comunicación masiva" y tiende hacia una politización de la cultura. De allí la descolonización de una cultura no se obtiene más que del fruto de la conciencia crítica de la misma, a partir del dimensionamiento histórico del neocolonialismo (y no sólo una "colonialidad" sin dimensión antropológica) adoptado. Por ello, Zea insiste desde el principio en la conscientización de la problemática de la sociedad, donde la difusión cultural universitaria parta desde los valores y principios de la sociedad en que se origina.

En tal sentido, las reformas universitarias latinoamericanas (como las del siglo XX con Argentina y la Universidad de Córdoba en 1918, entre muchas otras) se han abocado y tendrán que seguir orientándose por el horizonte de la interpretación racional de la realidad. Esto es, que toda reforma educativa (universitaria en este caso) considere como horizonte no solamente una descripción de la realidad donde se sitúan, sino también una interpretación crítica de lo que nos es propio.

Es aquí que se precisa democratizar la educación y educar en la democracia, a partir de la polémica como actividad práctica que permita dimensionar los principios mínimos de toda convivencia social, para una conciencia orientadora, esto es, educativa, inclusiva de toda persona humana y sin campo para toda aculturación. En tal sentido afirma Zea que «más que difundir la cultura, esto es, los productos de la conciencia crítica enfrentando la realidad, lo que hay que difundir es la actitud crítica [...], es la conveniencia de la capacidad crítica del hombre, de cualquier hombre frente a la realidad en que se encuentra inmerso». ¿Por qué? 
Porque «la conciencia crítica de la realidad, incluyendo la organización social a través de la cual se expresan, [es] lo que hace posible la historia», una historia que se oriente hacia una solidaridad libre y justa por una integración realmente posible (Zea, 1980, pp. 89, 91).

\section{REFLEXIONES FINALES}

Podemos decir entonces que una auténtica difusión cultural ha sido tema pendiente en nuestras dañadas y violentadas naciones de nuestra América. El sólo tema de acceso a una educación básica y no básica (superior) pública y de calidad, es de suficiente consideración al respecto.

Actualmente, gran parte de las instituciones de educación se encuentran cooptadas por un modelo neoliberal educativo donde el individualismo, la eficiencia y la eficacia se realizan en competencias ególatras que marcan las desigualdades sociales. Ni hablar de las instituciones privadas. Tal es el principio de realidad ante el que se hace necesaria una antropoliética, en tanto horizonte de rescate de la persona humana en su situación concreta.

La pandemia actual ha venido a agudizar las desigualdades sociales y a evidenciar la violencia estructural y sacrificial de la que todos hemos sido parte en algún momento. Violencia estructural, que lleva a privatizar el espacio público y a hacer público espacios privados y hasta íntimos (o, en otros términos, entender que el trabajo y la escuela se ha metido a nuestras casas) donde, no obstante, los "poderosos medios de comunicación", a pesar de su sentido "anti-cultural", han demostrado ser un instrumento útil para mantener diálogos como el que aquí nos convoca y poder realizar un intercambio a muy pequeña escala, que colabora como signo de solidaridad regional de nuestra América para una verdadera integración. Instrumentalización de los "poderosos medios de comunicación" que es preciso potenciar para poder realizar los fines educativos de un pensamiento crítico en un marco democrático radical.

¿Dónde situar la tarea de los docentes y distintos intelectuales que conforman instituciones de difusión cultural? Justamente en una actitud militante que permita una integración con la cultura popular que, desde planteamientos como los de Zea o Magallón (y acaso más allá de ellos), hay que vincular las instituciones con la colectividad que la posibilita y da cobijo, no solamente abriendo las instituciones al pueblo, sino el pueblo a las instituciones a través de distintos micro-espacios que permitan el diálogo concreto efectivo desde una posición crítica y autocrítica de la realidad, por una liberación e integración humana, más allá de cualquier marco civilizatorio represivo y cualquier culturalismo opresor.

\section{REFERENCIAS}

Ardiles, Osvaldo. (1975). Ethos, cultura y liberación. Cultura popular y filosofía de la liberación. Fernando García Cambeiro, pp. 9-32.

Bartra, Roger. (2014). Antropología del cerebro. FCE. 
Clastrés, Pierre. (1987). Sobre el etnocidio. Investigaciones en antropología política. Gedisa, pp. 55-65.

Elías, Norbert. (2019). El proceso de la civilización. FCE.

Kant, Immanuel. (2003). Pedagogía. Akal.

Laín Entralgo, Pedro. (1968). Teoría y realidad del otro. Tomo II: Otredad y projimidad. Revista de Occidente.

Magallón, Mario. (2010). Antropología ética de la educación en tiempos posmodernos en Educación Superior. Cifras y Hechos, 8 (49-50), enero-abril, pp. 12-13.

. (2010b). Historia de las ideas filosóficas (ensayo de filosofía y de la cultura en la mexicanidad). Editorial Torres y Asociados.

(1993). Filosofía política de la educación en América Latina, CCyDEL/UNAM.

Marcuse, Herbert. (1965). Eros y civilización. Joaquín Mortiz.

Mélich, Joan Carles. (1996). Antropología simbólica y acción educativa. Paidós.

Morín, Edgar. (1999). Siete saberes necesarios para la educación del futuro. UNESCO.

Ricoeur, Paul. (2003). La memoria, la historia, el olvido. FCE.

Ricoeur, Paul. (2009). Educación y política. UCA/Prometeo libros.

Silvero, José M. (2014). Suciedad, cuerpo y civilización. UNA.

Todorov, Tzvetan (1996). Los abusos de la memoria. Paidós. (2013). El miedo a la barbarie. Galaxia Gutenberg.

Villalpando, José M. (1966). Pedagogía comparada. Teoría y técnica. Porrúa.

Zea, Leopoldo. (1974). Dependencia y liberación en la cultura latinoamericana. Joaquín Mortiz.

(1980). Sentido de la difusión cultural latinoamericana. UNAM.

(1986). América como autodescubrimiento. Universidad Central.

(1988). Discurso desde la marginación y la barbarie. Anthropos. 